\title{
APROVEITAMENTO INDUSTRIAL DO UMBU: PROCESSAMENTO DE GELÉIA E COMPOTA
}

\author{
MARÍLIA I. S. FOLEGATTI ${ }^{1}$ \\ FERNANDO C. A. U. MATSUURA ${ }^{2}$ \\ RICARDO L. CARDOSO ${ }^{3}$ \\ SÉRLY S. MACHADO ${ }^{4}$ \\ ANDRÉA S. ROCHA \\ RENATA R. LIMA ${ }^{5}$
}

\begin{abstract}
RESUMO - O umbu (Spondias tuberosa Arr. Cam.) é uma fruta nativa da Região Nordeste do Brasil. Ainda não devidamente caracterizado, particularmente no que se refere ao seu potencial para industrialização, o umbu demanda pesquisas. Atualmente, esses frutos são consumidos restritamente na região Nordeste, principalmente na forma in natura, preparados como refresco, sorvete ou "umbuzada" (polpa do umbu cozida com leite e açúcar). Objetivou-se com este trabalho adequar a tecnologia convencional de processamento de geléia e compota para o umbu, avaliando a aceitação sensorial e as características físico-químicas desses produtos. Para o processamento de geléia, utilizaram-se duas proporções polpa/açúcar: 50:50 e 40:60, e três concentrações de sólidos insolúveis da polpa: $0 \%, 50 \%$ e $100 \%$ do teor de sólidos original da polpa. Para a compota, elabora-
\end{abstract}

ram-se produtos com diferentes teores de sólidos solúveis finais, $25^{\circ}$ Brix, $30^{\circ}$ Brix e $35^{\circ}$ Brix, adicionados de $1 \%$ de cloreto de cálcio. As polpas, geléias e compotas dos diferentes tratamentos foram submetidas a análises físicas, físico-químicas, químicas e sensoriais. No processamento da geléia de umbu, os produtos obtidos apresentaram valores de acidez total titulável entre $0,60 \%$ e $0,90 \%$ e de sólidos soúveis totais entre $66,3^{\circ}$ Brix e $68,6^{\circ}$ Brix. Os tratamentos com proporção polpa:açúcar 50:50 foram significativamente ( $\mathrm{p} \leq 0,05)$ mais bem aceitos quanto aos atributos aparência, cor e textura. Para o produto compota de umbu, os tratamentos com $30^{\circ}$ Brix e $35^{\circ}$ Brix obtiveram maior aceitação sensorial. $\mathrm{O}$ aproveitamento do umbu na forma de geléia ou compota mostrou-se possível, tendo os produtos desenvolvidos apresentado boa aceitação sensorial.

TERMOS PARA INDEXAÇÃO: Spondias, industrialização, aceitação sensorial, umbu.

\section{INDUSTRIAL USE OF UMBU: JELLY AND FRUIT-IN-SYRUP PROCESSING}

\begin{abstract}
The umbu (Spondias tuberosa Arr. Cam.) is a native fruit of the Brazilian Northeast region.. The umbu demands research as it is not adequately characterized, particularly considering its potential for industrialization. Nowadays, these fruits are consumed, at the Northeast region, mainly in natura, prepared as juice, ice cream or "umbuzada" (pulp of the umbu cooked with milk and sugar). The
\end{abstract}

objective of this work was to adapt conventional technology to process umbu jelly and fruit-in-syrup, by evaluating the sensorial acceptance and the physicochemical characteristics of these products. For the jelly processing, it was used two pulp:sugar proportions, 50:50 and 40:60, and three concentrations of insoluble solids of the pulp, $0 \%, 50 \%$ and $100 \%$ of the original insoluble solids pulp content. For the

1. Zootecnista, Embrapa Mandioca e Fruticultura, Laboratório de Ciência e Tecnologia de Alimentos, Rua Embrapa $\mathrm{s} / \mathrm{n}^{\circ}$, Caixa Postal 07, 44380-000, Cruz das Almas, BA.

2. Engenheiro Agrônomo, Embrapa Mandioca e Fruticultura. Laboratório de Ciência e Tecnologia de Alimentos.

3. Engenheiro de Alimentos, Escola de Agronomia da Universidade Federal da Bahia, Departamento de Química Agrícola, Campus Universitário, 44380-000, Cruz das Almas, BA.

4. Engenheiro Agrônomo, Universidade Estadual de Feira de Santana, Departamento de Tecnologia, Km 3, BR116, Campus Universitário s $/ \mathrm{n}^{\circ}, 44.031-580$, Feira de Santana, BA.

5. Estudantes de Engenharia Agronômica, Escola de Agronomia da Universidade Federal da Bahia. 
umbu-in-syrup, the products were elaborated with different concentration of final soluble solids, $25^{\circ}$ Brix, $30^{\circ}$ Brix and $35^{\circ}$ Brix, added of $1 \%$ calcium chloride. The pulps, jellies and fruits-in-syrup of the different treatments were submitted to physical, physicochemical, chemical and sensorial analyses. In the processing of the umbu jelly, the end products presented values of total titratable acidity between $0.60 \%$ and $0.90 \%$ and soluble solid contents between $66.3^{\circ}$ Brix and $68.6^{\circ}$ Brix. The treatments with proportion pulp:sugar 50:50 had significantly ( $\mathrm{p} \leq$ 0,05 ) highest sensorial acceptance in relation to the attributes appearance, color and texture. The global acceptance of the umbu fruit-in-syrup was highest for the treatments with $30^{\circ}$ Brix and $35^{\circ}$ Brix. The use of the umbu fruit as jelly or fruit-in-syrup is possible as these products presented good sensorial acceptance.

INDEX TERMS: Spondias, industrialization, sensory acceptance, umbu.

\section{INTRODUÇÃO}

O umbuzeiro (Spondias tuberosa Arr. Cam.) é uma fruteira nativa de regiões semi-áridas do Nordeste brasileiro. É uma planta xerófila, caducifólia, da família das anacardiáceas, adaptada ao calor, aos solos pobres e à falta de água. É uma árvore de pequeno porte, de copa em forma de guarda-chuva, esparramada, de tronco curto, com galhos retorcidos e muito ramificados (MENDES, 1990).

Os frutos, conhecidos como umbu, imbu ou ambu, são drupas glabras ou levemente pilosas, arredondadas, com $2 \mathrm{~cm}$ a $4 \mathrm{~cm}$ de diâmetro, $10 \mathrm{~g}$ a $20 \mathrm{~g}$ de massa e superfície lisa ou com 4 a 5 pequenas protuberâncias na porção distal (MENDES, 1990). A casca é de cor amarelo-esverdeada e a polpa é brancoesverdeada, mole, suculenta, de sabor agridoce agradável (SILVA e SILVA, 1974; SILVA et al., 1987). Os frutos são constituídos, em média, por $22 \%$ de casca, $68 \%$ de polpa e $10 \%$ de caroço (MENDES, 1990). Cavalcanti et al. (2000) obtiveram rendimento de polpa entre $62 \%$ e $75 \%$, de acordo com o estádio de maturação dos frutos.

Souza e Catão (1970) encontraram $87,8 \%$ de umidade, $8,34 \%$ de açúcares totais, $1,57 \%$ de acidez (em ácido tartárico) e 31,2 mg de vitamina C em $100 \mathrm{~g}$ de polpa de frutos de umbu recém-colhidos. Bispo (1989) analisou a polpa de umbu, encontrando $89,9 \%$ de umidade, $7,95 \%$ de açúcares totais, $0,52 \%$ de proteínas, $0,35 \%$ de lipídeos, $0,37 \%$ de fibras, $0,35 \%$ de cinzas e acidez total titulável de 1,23\% (em ácido cítrico), $\mathrm{pH}$ de 2,45, 9,61 mg de ácido ascórbico/100 g, 0,82\% de pectina e 126,27 $\mathrm{mg}$ de taninos/100 g.

Os frutos de umbuzeiro apresentam apelo "exótico" para mercados de outras Regiões do Brasil, como Sudeste e Sul, e para o mercado externo, o que vem estimulando o aumento de sua produção. Ainda não devidamente caracterizado, particularmente no que se refere ao seu potencial para industrialização, o umbu é uma fruta que demanda pesquisas. Entre as demandas de pesquisa, ressaltam-se a adequação de tecnologias convencionais e o desenvolvimento de novas tecnologias para o processamento dessa fruta, de forma a promover um aproveitamento mais rentável, mediante a agregação de valor a esse produto. Atualmente, esses frutos são consumidos restritamente na região Nordeste do Brasil, principalmente na forma in natura ou preparados como refresco, sorvete e "umbuzada" (polpa do umbu cozida com leite e açúcar).

Bispo (1989) elaborou uma geléia de umbu com $67,6^{\circ}$ Brix, $59 \%$ de suco filtrado, sem adição de pectina, em tacho aberto, obtendo um produto com elevada aceitação sensorial de cor e sabor, $\mathrm{pH}$ de 2,37 e $0,55 \%$ de acidez total titulável. Nesse mesmo experimento, a geléia apresentou escurecimento gradual durante o armazenamento por 120 dias, em condições ambiente, diminuindo a aceitação da cor do produto.

Conduziu-se este trabalho com o objetivo de adequar a tecnologia convencional de processamento de geléia e compota para frutos de umbu, avaliando a aceitação sensorial e as características físico-químicas desses produtos.

\section{MATERIAL E MÉTODOS}

\section{Processamento}

Nos processamentos de geléia e de compota de umbu, foram utilizados frutos colhidos ligeiramente amarelados, obtidos de produtor comercial, açúcar (sacarose) e pectina.

As geléias e as compotas foram elaboradas conforme procedimento convencional (JACKIX, 1988) e embaladas em potes de vidro com tampa metálica. No processamento da geléia, utilizaram-se duas proporções polpa:açúcar, 50:50 e 40:60, e três concentrações de sólidos insolúveis da polpa, $0 \%, 50 \%$ e $100 \%$ do teor de sólidos original da polpa, enquanto no da compota, 
empregaram-se xaropes com diferentes teores de sólidos solúveis totais para a obtenção de produtos finais com $25^{\circ}$ Brix, $30^{\circ}$ Brix e $35^{\circ}$ Brix e adicionados de $1 \%$ de cloreto de cálcio, em relação ao peso dos frutos, visando a manter a textura firme dos frutos.

\section{Análises}

\section{Análises físicas, físico-químicas e químicas}

Os frutos, as geléias e as compotas foram analisados quanto ao $\mathrm{pH}$ (por leitura direta em potenciômetro), teor de acidez total titulável (AOAC, 1995), teor de sólidos soúveis totais (por medida direta em refratômetro) e vitamina C (AOAC, 1995).

As compotas também foram analisadas quanto ao vácuo (por medida com vacuômetro), espaço livre (por medida com régua graduada), peso bruto, peso líquido, peso drenado (medidos em balança semianalítica), número de frutos por pote, volume de xarope (medido em proveta graduada) e aspecto do xarope (com o uso de uma escala numérica, com graus de turvação de $1=$ sem turvação a $5=$ muito turvo).

\section{Análise sensorial}

As geléias e compotas foram avaliadas quanto aos atributos aparência, cor, aroma, sabor, textura e aceitação global em testes de consumidor, utilizando-se escala hedônica estruturada de 9 pontos $(1=$ desgostei extremamente; 2 = desgostei muito; 3 = desgostei moderadamente; 4 = desgostei ligeiramente; $5=$ nem desgostei, nem gostei; 6 = gostei ligeiramente; 7 = gostei moderadamente; 8 = gostei muito; 9 = gostei extremamente).

Para a geléia, também foram avaliados os atributos doçura, acidez e firmeza, utilizando-se escala do ideal estruturada de 9 pontos $(1=$ extremamente menor que o ideal; 2 = muito menor que o ideal; 3 = moderadamente menor que o ideal; $4=$ ligeiramente menor que o ideal; 5 = ideal; $6=$ ligeiramente maior que o ideal; $7=$ moderadamente maior que o ideal; $8=$ muito maior que o ideal; 9 = extremamente maior que o ideal).

A ordem de apresentação das amostras foi balanceada, para ambas as avaliações, utilizando-se um modelo estatístico (WAKELING e MACFIE, 1995). Foram realizadas três sessões, com 24 provadores, potenciais consumidores do produto.

\section{Análise estatística}

Os resultados das análises físico-químicas foram submetidos à análise estatística descritiva, enquanto os da sensorial, à análise de variância e de comparação de médias (teste Tukey). O delineamento utilizado foi o inteiramente casualizado (GOMES, 1973), considerandose seis tratamentos para a geléia e três tratamentos para a compota.

\section{RESULTADOS E DISCUSSÃO}

\section{Geléia de umbu}

A polpa utilizada no processamento da geléia apresentou valores médios de $\mathrm{pH}$ de 2,82, teor de acidez total titulável (ATT) de 1,56\% (em ácido cítrico), de sólidos solúveis totais (SST) de $10,0^{\circ}$ Brix e de ácido ascórbico de 7,65 mg/100 g. O pH e o teor de ATT foram superiores e o teor de ácido ascórbico foi próximo aos valores encontrados por Bispo (1989). Neste experimento, a polpa de umbu apresentou-se como uma matéria-prima de $\mathrm{pH}$ baixo, alta acidez, médio teor de sólidos solúveis e baixo teor de ácido ascórbico.

As geléias obtidas apresentaram valores de $\mathrm{pH}$ entre 2,82 e 3,05, teores de ATT entre $0,62 \%$ e $0,88 \%$ (em ácido cítrico) e de SST entre $66,3^{\circ}$ Brix e $68,6^{\circ}$ Brix (Tabela 1). Esses valores diferiram das geléias elaboradas por Bispo (1989), com pH muito baixo, de 2,37, e teor de ATT de 0,55\%. Essa diferença deveu-se, provavelmente, à diferença de composição da matéria-prima. $\mathrm{O}$ pH e o teor de ATT da polpa utilizada nesse processamento foram superiores aos valores da polpa empregada por Bispo (1989).O aumento da quantidade de polpa adicionada, ou seja, 50:50, em comparação a 40:60, resultou no aumento do teor de ATT dos produtos e ligeira diminuição do $\mathrm{pH}$. A variação do teor de sólidos insolúveis da polpa praticamente não afetou o teor de ATT e pH das geléias produzidas nos tratamentos com proporção polpa:açúcar 50:50 e 40:60.

Os tratamentos com proporção polpa:açúcar 50:50, com $0 \%, 50 \%$ e $100 \%$ de sólidos insolúveis da polpa, foram mais bem aceitos sensorialmente que os com proporção 40:60, em relação aos atributos aparência (notas entre 7, gostei moderadamente, e 8, gostei muito), cor (notas entre 7 e 8 ) e textura (notas próximas a 7), diferindo significativamente $(\mathrm{p} \leq 0,05)$ entre si (Figura 1), e se aproximaram mais do ideal quanto ao atributo firmeza (notas próximas a $5=$ firmeza ideal) (Figura 2). A maior quantidade de polpa nos tratamentos com proporção 50:50 promoveu uma melhor aceitação da cor da geléia, provavelmente em razão de o produto final apresentar-se menos escurecido. Os tratamentos com proporção 40:60 apresentaram baixos valores para o atributo aparência, próximos a 5,0 (nem gos- 
tei e nem desgostei), sendo significativamente menores que os com proporção 50:50. Provavelmente, a coloração mais escura e amarronzada dos tratamentos 40:60 também influiu negativamente na avaliação da aparência dos produtos.

As geléias não apresentaram diferença significativa em relação aos atributos aroma e sabor, o que mostra que esses atributos não foram influenciados pela proporção polpa:açúcar e pelo teor de sólidos insolúveis da polpa utilizada no processamento e demonstra que as substâncias responsáveis pelo aroma e sabor encontravam-se em níveis suficientes na proporção 40:60 e dissolvidas no soro da polpa utilizada.

Entre os tratamentos com proporção polpa:açúcar 50:50, o tratamento com 100\% de sólidos insolúveis da polpa, comparado aos com $0 \%$ e $50 \%$, recebeu as menores notas para todos os atributos avaliados; entretanto, essa diferença não foi significativa.

A doçura, acidez e firmeza dos produtos foram próximas do ideal, exceto para o tratamento T2 (doçura e firmeza). As geléias com maior proporção polpa:açúcar (50:50) apresentaram valores mais próximos do ideal para a firmeza. Os resultados da acidez não diferiram significativamente $(\mathrm{p} \leq 0,05)$ entre si (Figura 2$)$.

\section{Compota de umbu}

Os frutos utilizados no processamento de compota apresentaram valores médios de $\mathrm{pH}$ de 2,83 , teor de SST de $10,8^{\circ}$ Brix, de ATT de $1,07 \%$ e de ácido ascórbico de 3,8 mg/100 g. Os teores de ATT e ácido ascórbico foram inferiores aos encontrados por Souza e Catão (1970) e Bispo (1989), enquanto o $\mathrm{pH}$ foi superior ao reportado por Bispo (1989), provavelmente e em parte por causa da origem e do estádio de maturação dos diferentes frutos.

As compotas de umbu correspondentes aos tratamentos com $25^{\circ}$ Brix, $30^{\circ}$ Brix e $35^{\circ}$ Brix apresentaram, respectivamente, os seguintes valores médios: vácuo de $17,7 \pm 0,27$ pol $\mathrm{Hg}^{-1}, 18,2 \pm 1,04$ pol $\mathrm{Hg}^{-1}$ e $19,1 \pm 1,24$ pol $\mathrm{Hg}^{-1}$; espaço livre de $7,1 \pm 1,37 \%, 8,4 \pm 0,90 \%$ e $10,2 \pm 1,33 \%$; peso bruto de $907,98 \pm 2,25 \mathrm{~g}, 917,94 \pm 8,01 \mathrm{~g}$ e $931,48 \pm 6,72 \mathrm{~g}$; peso líquido de $622,71 \pm 2,26 \mathrm{~g}, 631,78 \pm 7,79 \mathrm{~g}$ e $645,13 \pm 6,84 \mathrm{~g}$; peso drenado de $350,90 \pm 10,79 \mathrm{~g}$, $348,67 \pm 10,58 \mathrm{~g}$ e $342,34 \pm 13,44 \mathrm{~g}$; número de frutos por pote de $22 \pm 1,21 \pm 1$ e $19 \pm 1$; volume do xarope de $246 \pm 12 \mathrm{~mL}, 252 \pm 16 \mathrm{~mL}$ e $258 \pm 11 \mathrm{~mL}$; aspecto do xarope igual a 2,0 (pequena turvação) para todos os tratamentos; e teor de SST de $23,1 \pm 0,2^{\circ}$ Brix, $28,6 \pm 1,5^{\circ}$ Brix e $36,2 \pm 0,8^{\circ}$ Brix. Quanto às demais análises físico-químicas e químicas, o $\mathrm{pH}$ foi próximo a 2,70 para todos os tratamentos; o teor de ATT variou de 1,07 a $1,22 \%$; e o teor de ácido ascórbico variou de $3,52 \mathrm{mg} / 100 \mathrm{~g}$ a $3,54 \mathrm{mg} / 100 \mathrm{~g}$. Portanto, o vácuo foi adequado, o $\mathrm{pH}$ do produto foi naturalmente baixo, o teor de acidez, regular e o teor de ácido ascórbico, baixo. O xarope apresentou pequena turvação, que poderá ser diminuída com outros ajustes no processamento. Ressalta-se o elevado número de frutos por pote.

TABELA 1 - Resultados das análises do teor de sólidos solúveis totais (SST), pH e acidez total titulável (ATT) das geléias de umbu.

\begin{tabular}{cccc}
\hline Material & SST $\left({ }^{\circ}\right.$ Brix $)$ & pH & ATT $(\%$ em ac. cítrico) \\
\hline Geléias 40:60 & & & \\
100\% SI & $67,5 \pm 1,1$ & $3,05 \pm 0,08$ & $0,62 \pm 0,07$ \\
$50 \%$ SI & $68,1 \pm 1,0$ & $2,91 \pm 0,08$ & $0,68 \pm 0,08$ \\
0\% SI & $68,6 \pm 0,8$ & $2,89 \pm 0,07$ & $0,62 \pm 0,04$ \\
\hline Geléias 50:50 & & & $0,86 \pm 0,10$ \\
$100 \%$ SI & $67,1 \pm 0,9$ & $2,82 \pm 0,09$ & $0,86 \pm 0,05$ \\
$50 \%$ SI & $66,3 \pm 1,0$ & $2,88 \pm 0,10$ & $0,88 \pm 0,06$ \\
\hline
\end{tabular}

Os resultados representam a média de 5 repetições

SI: sólidos insolúveis da polpa (em relação ao teor original) 


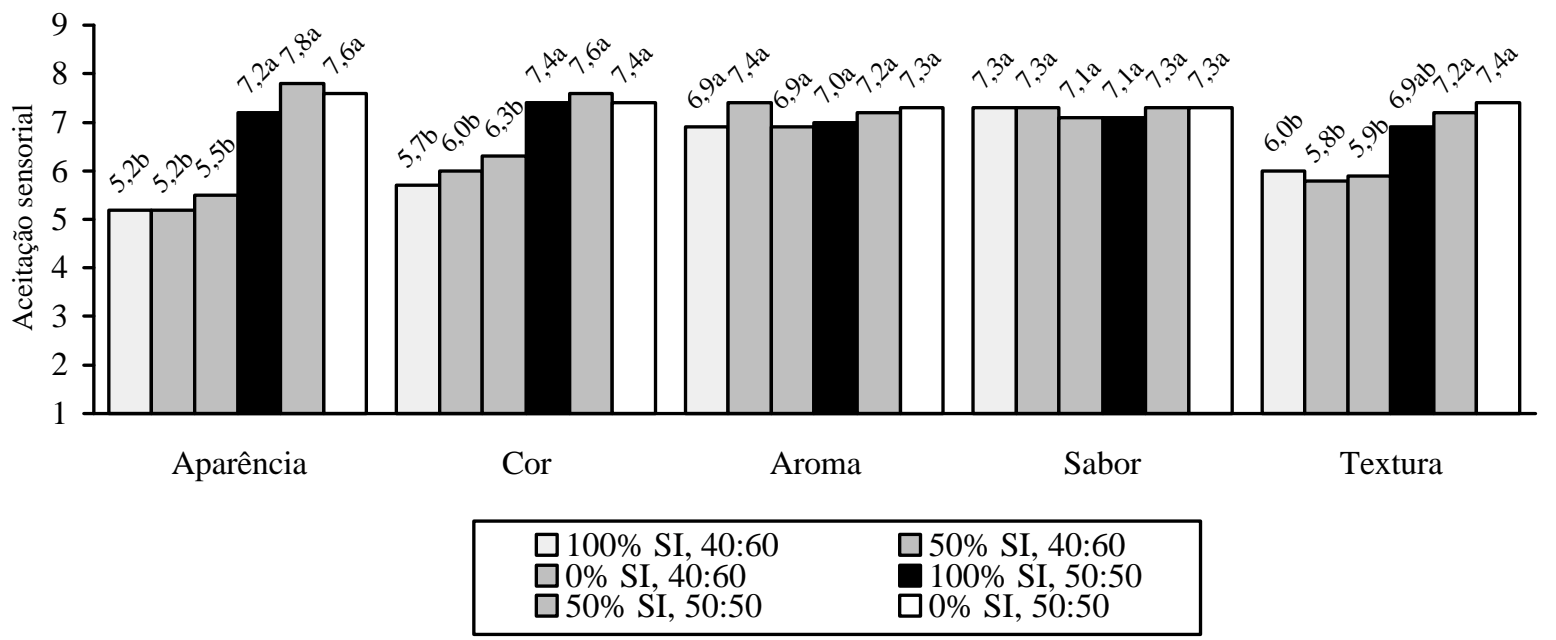

SI: sólidos insolúveis da polpa (em relação ao teor original)

Para cada atributo avaliado, tratamentos com letras diferentes diferem a 5\% de significância.

FIGURA 1 - Resultados dos testes sensoriais de aceitação das geléias de umbu quanto aos atributos aroma, sabor, textura, aparência e cor. Escala hedônica de 9 pontos ( 1 = desgostei extremamente; $5=$ nem desgostei, nem gostei; $9=$ gostei extremamente).

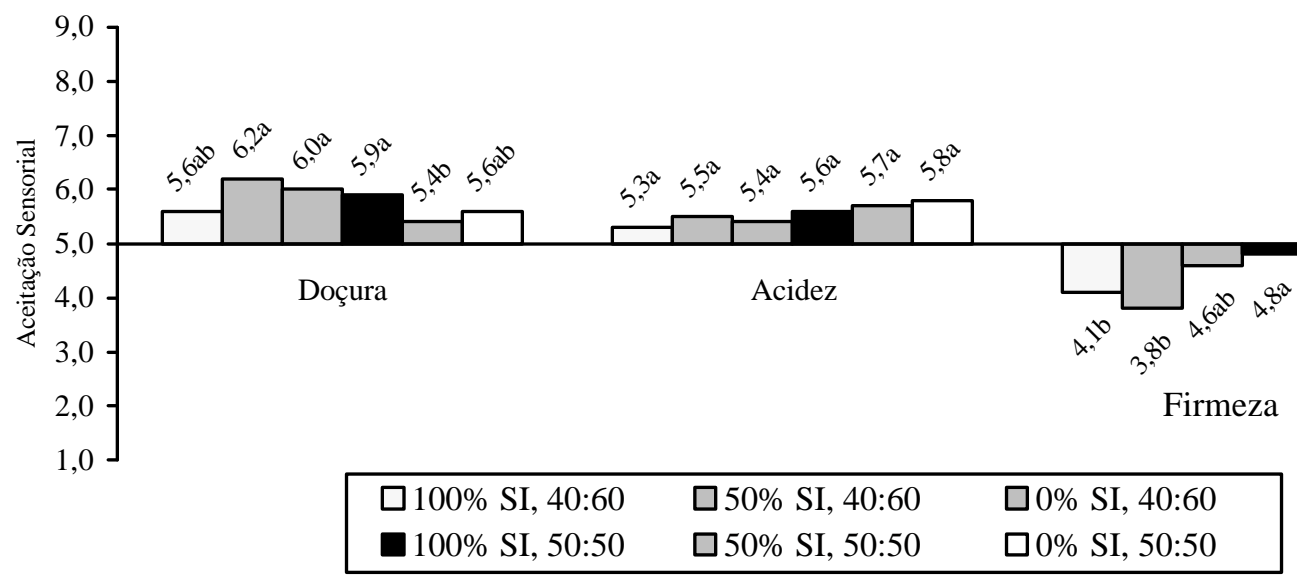

SI: sólidos insolúveis da polpa (em relação ao teor original)

Para cada atributo avaliado, tratamentos com letras diferentes diferem a 5\% de significância.

FIGURA 2 - Resultados dos testes sensoriais de aceitação das geléias de umbu quanto aos atributos doçura, acidez e firmeza. Escala do ideal $(1=$ extremamente menor que o ideal; $5=$ ideal; $9=$ extremamente maior que o ideal). 


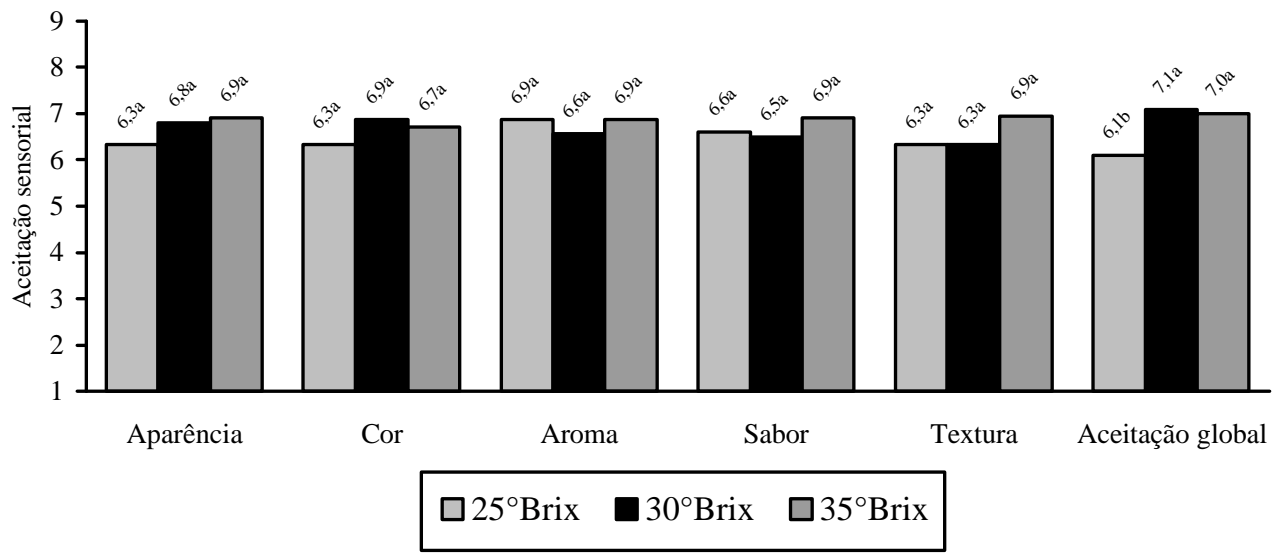

FIGURA 3 - Resultados dos testes de aceitação sensorial das compotas de umbu com $25^{\circ}$ Brix, $30^{\circ}$ Brix e $35^{\circ}$ Brix quanto aos atributos aparência, cor, aroma, sabor, textura e aceitação global. Escala hedônica de 9 pontos $(1=$ desgostei extremamente; 5 = nem desgostei, nem gostei; 9 = gostei extremamente).

Quanto à análise sensorial, a compota com $35^{\circ}$ Brix recebeu as maiores notas para os atributos aparência, aroma, sabor e textura, próximos a 7 (gostei moderadamente); entretanto, essas notas não diferiram significativamente $(\mathrm{p} \leq 0,05)$ das dos demais tratamentos. Para a aceitação global, as compotas com $30^{\circ}$ Brix e $35^{\circ}$ Brix obtiveram valores próximos a 7 , não diferindo significativamente entre si, mas diferindo da compota com $25^{\circ}$ Brix, que obteve nota próxima a 6 (gostei ligeiramente) (Figura 3), demonstrando que as compotas com maior teor de sólidos solúveis totais foram as mais aceitas. Talvez o aumento do teor de sólidos solúveis totais do produto final, acima dos teores estudados no presente trabalho, possa melhorar a qualidade sensorial do produto, particularmente quanto ao sabor. Em todos os tratamentos ocorreu um ligeiro desprendimento da casca dos frutos, problema que ainda requer solução em estudos futuros.

\section{CONCLUSÕES}

O aproveitamento do umbu na forma de geléia ou compota mostrou-se possível, tendo os produtos desenvolvidos apresentado boa aceitação sensorial. A geléia de umbu mais aceita foi a produzida com proporção polpa:açúcar de 50:50, ao passo que para a compota houve uma relação direta entre a aceitação sensorial e o teor final de sólidos solúveis totais, sendo o produtos finais com $30^{\circ}$ Brix e $35^{\circ}$ Brix os mais bem aceitos sensorialmente.

\section{AGRADECIMENTOS}

Ao Ministério da Agricultura, Pecuária e Abastecimento, pelo apoio financeiro, e às empresas Brasfrut, Copersucar, CP Kelco, Nadir Figueiredo e Rojek, pelo fornecimento dos materiais usados neste trabalho.

\section{REFERÊNCIAS BIBLIOGRÁFICAS}

ASSOCIATON OF OFFICIAL ANALYTICAL CHEMISTS. Official methods of analysis. 16. ed. Arlington, 1995. $1141 \mathrm{p}$.

BISPO, E. da S. Estudo de produtos industrializáveis do umbu (Spondias tuberosa, Arr. Câmara). 1989. 119 f. Dissertação (Mestrado em Tecnologia de Alimentos) - Universidade Federal do Ceará, Fortaleza, 1989.

CAVALCANTI, N. de B.; RESENDE, G. M.; BRITO, L. T. de L.; ANJOS, J. B. dos; ARAÚJO, F. P. de. Doce de imbu. Petrolina: EMBRAPA Semiárido, 2000. 6 p. (EMBRAPA. Instruções técnicas, 36).

GOMES, F. P. Curso de estastística experimental. 5. ed. São Paulo: Nobel, 1973. 468 p.

JACKIX, M. H. Doces, geléias e frutas em calda. Campinas: UNICAMP, 1988. 172 p. 
MENDES, B. V. Umbuzeiro (Spondias tuberosa Arr. Cam.): importante fruteira do semi-árido. Mossoró: ESAM, 1990. 63 p. (ESAM. Coleção Mossorense, série C, v. 564).

SILVA, A. Q. da; SILVA, M. A. da G. O. Observações morfológicas e fisiológicas sobre Spondias tuberosa A. Cam. In: CONGRESSO NACIONAL DE BOTÂNICA, 25., 1974, Mossoró. Anais... Recife: Sociedade Botânica do Brasil, 1976. p. 5-15.

SILVA, C. M. M. de S.; PIRES, I. E.; SILVA, H. D. da. Caracterização dos frutos do umbuzeiro. Petroli- na: EMBRAPA-CPATSA, 1987. 17 p. (EMBRAPA. Boletim de pesquisa, 34).

SOUZA, A. H. de; CATÃO, D. D. Umbu e seu suco. Revista Brasileira de Farmácia, Rio de Janeiro, v. 51, p. 335-353, 1970.

WAKELING, I. N.; MACFIE, J. H. Designing consumer trials balanced for first and higher orders of carry-over effect when only a subset of $\mathrm{k}$ samples from $\mathrm{t}$ may be tested. Food Quality and Preference, Oxford, v. 6, p. 299-308, 1995. 